This is an author produced version of a paper published in Frontiers In Ecology And The Environment.

This paper has been peer-reviewed and includes the final publisher proofcorrections and journal pagination.

Citation for the published paper:

Olivia Odom Green, Ahjond S Garmestani, Craig R Allen, Lance H Gunderson, JB Ruhl, Craig A Arnold, Nicholas AJ Graham, Barbara Cosens, David G Angeler, Brian C Chaffin, and CS Holling. (2015) Barriers and bridges to the integration of social-ecological resilience and law. Frontiers In Ecology And The Environment. Volume: 13, Number: 6, pp 332337.

http://dx.doi.org/10.1890/140294.

Access to the published version may require journal subscription. Published with permission from: Ecological Society of America.

Standard set statement from the publisher:

Copyright by the Ecological Society of America

Epsilon Open Archive http://epsilon.slu.se 


\title{
Barriers and bridges to the integration of social-ecological resilience and law
}

\author{
Olivia Odom Green ${ }^{1 *}$, Ahjond S Garmestani ${ }^{2}$, Craig R Allen ${ }^{3}$, Lance H Gunderson ${ }^{4}$, JB Ruhl ${ }^{5}$, Craig A Arnold ${ }^{6}$, \\ Nicholas AJ Graham ${ }^{7}$, Barbara Cosens ${ }^{8}$, David G Angeler ${ }^{9}$, Brian C Chaffin ${ }^{2}$, and CS Holling ${ }^{10}$
}

There is a fundamental difference between the ways in which ecologists and lawyers view uncertainty: in the study of ecology, uncertainty provides a catalyst for exploration, whereas uncertainty is antithetical to the rule of law. This issue is particularly troubling in environmental management, where the tensions between law and ecology become apparent. Rather than acknowledge uncertainties in management actions, legal frameworks often force a false sense of certainty in linking cause and effect. While adaptive management has been developed to deal with uncertainty, laws and legal wrangling can be obstacles to implementation. In this article, we recommend resilience-based governance - "adaptive governance" - as a means to begin bridging the gap between law and ecology.

Front Ecol Environ 2015; 13(6): 332-337, doi:10.1890/140294

$\mathrm{E}$ cologists and lawyers deal with uncertainty in very different ways. Ecologists and environmental scientists approach uncertainty as an opportunity to do research, while lawyers (including judges) often view uncertainty as a barrier to enforceability and action. This tension at the intersection of law and science is particularly troublesome for environmental management. As a collaboration of ecologists and legal scholars, we suggest that adaptive governance can bridge this gap.

Adaptive governance is becoming more popular in the

\section{In a nutshell:}

- Environmental laws do not reflect the findings of the past 40 years of ecological research, particularly those findings that describe non-linear responses to disturbance (eg regime shifts)

- Previous calls for resilience-based governance that reflects these ecological findings are often seen in the ecological, social science, and legal literature (eg adaptive management, adaptive governance), but those fields rarely collaborate on how to reform the law

- Legal reforms must be enforceable, which requires the expertise of legal scholars; to be adaptive, legal reforms must also adjust based on current and future ecological knowledge, which necessitates the expertise of ecologists

${ }^{1}$ Atlantic States Legal Foundation, Syracuse, NY * (ogreen@aslf.org); ${ }^{2}$ US Environmental Protection Agency, Cincinnati, OH; ${ }^{3} \mathrm{US}$ Geological Survey-Nebraska Cooperative Fish and Wildlife Research Unit, University of Nebraska-Lincoln, Lincoln, NE; ${ }^{4}$ Department of Environmental Sciences, Emory University, Atlanta, GA; ${ }^{5}$ Vanderbilt University Law School, Nashville, TN; ${ }^{6}$ University of Louisville, Brandeis School of Law and Department of Urban and Public Affairs, Louisville, KY; ${ }^{7}$ ARC Centre of Excellence for Coral Reef Studies, James Cook University, Townsville, Australia; ${ }^{8}$ University of Idaho College of Law, Moscow, ID; ${ }^{9}$ Swedish University of Agricultural Sciences, Department of Aquatic Sciences and Assessment, Uppsala, Sweden; ${ }^{10}$ University of Florida, Gainesville, FL ecological and social science fields because it incorporates many well-established principles, such as the structured, hypothesis-driven process of adaptive management (Allen et al. 2011), into a broader model that addresses scale and social dimensions in environmental issues (Folke et al. 2005; Chaffin et al. 2014). However, the current discussion lacks an essential element: law. In much of the previous literature on adaptive governance, law is treated as an inconsequential aspect of the conditions necessary for achieving adaptive governance and essential legal questions, such as enforceability, are often ignored (Garmestani et al. 2013). The goal of this paper is to explicitly contribute the voice of law to adaptive governance scholarship by first exploring the tensions between ecology and US environmental law and then offering proposals to overcome several current legal obstacles to adaptive governance. Because law is inherently restricted to jurisdictional boundaries, our analysis is limited to US law, although many of the constraints of the US legal system are also relevant in other jurisdictions (see Green et al. 2013).

\section{Barriers to the integration of social-ecological resilience and law}

Environmental and procedural laws control environmental management but are based on outdated notions of ecosystem dynamics. Complexity and uncertainty are sometimes arbitrarily dealt with by breaking complex systems down into seemingly manageable parts and then assuming that managing these parts addresses the entire social-ecological system. Dealing with uncertainty in this way does not take into account current ecological knowledge about the capacity for unanticipated responses and interdependencies in ecosystems, and so may unintentionally limit our ability to understand critical ecosystem behaviors. 
Many ecosystems exhibit multiple regimes and non-linear dynamics (Angeler et al. 2013). Indeed, resilience theory emerged based on a growing knowledge of unexpected, abrupt changes in ecosystems. Resilience defines a system's capacity to absorb change (Holling 1973). When that capacity is exceeded, the system may cross a threshold and reorganize into a regime characterized by a different set of processes, feedbacks, and structures. These new regimes are often undesirable (eg oligotrophic versus eutrophic lakes) because they provide less valuable ecosystem goods and services. To maintain a desirable regime or to cross a threshold into a more desirable regime, researchers have advocated for policies that facilitate the ability to identify thresholds, cope with unexpected regime changes, and reduce uncertainties by learning more about a system rather than following the traditional environmental management approach of trying to control nature (Folke et al. 2004; Garmestani et al. 2013).

In contrast, the law is a tool for securing certainty in human affairs. Our legal system is designed to promote social stability through reliance on precedent, prescriptive rules, and adherence to procedure. In theory, this ensures fair treatment among parties involved in disputes, resolves conflicts, and fosters economic investment and civil society, all of which are advantageous social goals. One disadvantage is rigidity in the face of change or new information. This trade-off - sacrificing flexibility for finality - is particularly troubling in the context of environmental law, where outdated laws govern ecosystems of great complexity undergoing rapid changes. In the long run, uncertain outcomes associated with environmental change may undermine social stability (Craig 2010; Arnold and Gunderson 2013).

In the US, the revolution in environmental law of the 1970s (eg the Clean Water Act) was largely based on the idea that science and technology could fix environmental problems and that ecosystems are sufficiently stable so that negative environmental impacts can be identified, and in some cases mitigated, prior to the implementation of actions, as if cause and effect are predictable (Garmestani and Allen 2014). Such predictions (eg prescriptive action) define "front-end" management, which is characterized by simplified predictions of environmental harms, costs, benefits, and ultimately the finality of process (Shapiro and Glicksman 2004). Front-end management is the norm of administrative law (the area of law that governs procedural activities of government agencies) as defined by the Administrative Procedures Act (the law that governs how government agencies propose and establish regulations), substantive and procedural environmental statutes, and internal agency regulations.

Laws developed in the 1970s require compliance with specific standards and measures. Such an approach can be effective in mitigating some forms of environmental degradation, particularly when the goal, and the technology required to achieve it, is clear; for example, marked reductions in water pollution are a result of setting strict technology standards for industrial end-of-pipe (ie point source) polluters. More complex problems, on the other hand, where sources of water pollution may be numerous and difficult to identify (eg non-point source pollution, such as agricultural runoff), are frequently not well suited to technology-based approaches alone (Panel 1).

Furthermore, public land and wildlife management is often based on the assumption of a "balance of nature", wherein systems can be managed to sustain or optimize that balance through regulatory prescriptions (eg maximum sustainable yield in fisheries). However, a "balance

\section{Panel 1. Water-quality law and ecosystem regime shifts}

Urbanization, industrialization, and shifting agricultural practices have all contributed to degradation in water quality throughout the US (NRC 200I). The landmark Clean Water Act (CWA) of 1972 has been largely successful in controlling point source discharges into the nation's waters (Houck 2002). In many North American lakes (eg Lake Erie), recurring algal blooms continue to occur in spite of the clean water legislation (Figure I). Such blooms represent a clear example of non-linear regime shifts in ecosystem structure and function, and have contributed to the development of resilience theory (Folke et al. 2004). Moreover, such events reveal that the loftiest goals of the CWA - to restore the chemical, physical, and biological integrity of US waters have yet to be realized. The National Research Council (NRC 200I) found that large scientific and technical uncertainties were a barrier to improved water quality, due to the complexity of ecosystems and the difficulty involved in addressing uncertainty in a systematic manner. Cosens and Stow (2014) suggested that water-quality issues remain problematic because of the lack of coordination between

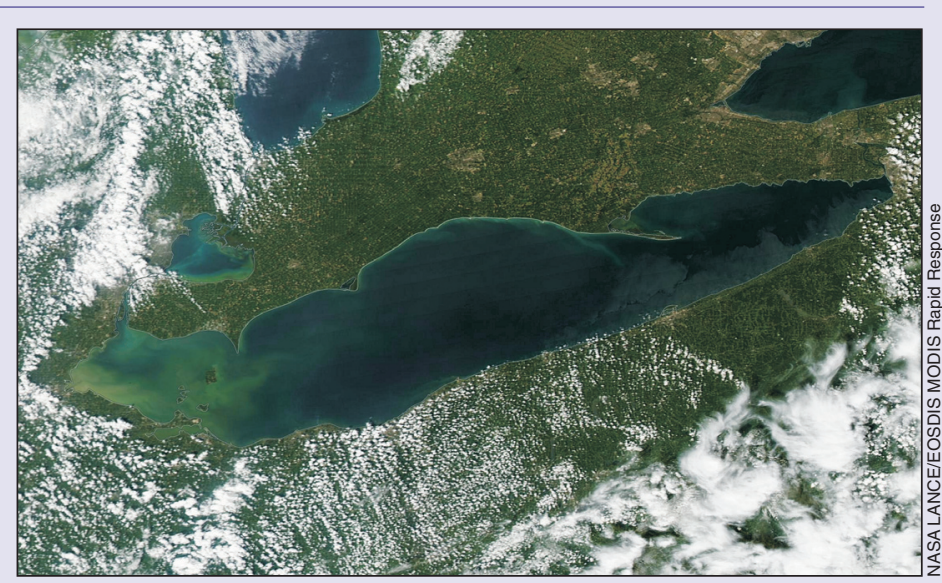

Figure 1. Algal bloom in Lake Erie, August 2014. The green portions of the lake are Microcystis algae. Such blooms represent a persistent and recurring environmental and public health problem (eg drinking water contamination in Toledo, Ohio, in August 2014). agencies charged with improving water quality and the need to establish learning networks that help managers understand why policies fail and how to develop new policies and management actions that recognize complexity and uncertainty. 
of nature" assumption is not relevant in the case of systems that can be pushed across a threshold and never return to "balance" (Ruhl 1997; McClanahan et al. 2011; Graham et al. 2015). In addition, artificially segmenting ecosystems into distinct management components (eg managing critical habitat for a single endangered species) or jurisdictions ignores the interdependent and cross-scale nature of ecosystems and the potential for deleterious overuse of natural resources (Garmestani and Allen 2014).

The certainty required by most legal approaches, assuming a balance of nature, does not account for the dynamic nature of social-ecological systems and does not recognize that solving environmental problems often requires the capacity to adapt in the face of change and to make trade-offs between competing societal and environmental goals.

\section{Bridges for the integration of social-ecological resilience and law}

We propose legal reforms to address uncertainty and complexity with adaptive governance. Such governance recognizes uncertainty as an integral component of the decision-making process and reduces uncertainty, not by eliminating variables (eg channelizing an urban stream to eliminate natural meandering processes) but by learning from the system through monitoring, feedback, and cycles of adaptation (Folke et al. 2005). Likewise, adaptive governance addresses complexity by embracing a systems approach to management rather than by breaking problems down into seemingly manageable parts that turn out to be ecologically or socially interdependent (eg fire suppression leading to more intense fires).

\section{Uncertainty}

Adaptive management is designed to address uncertainty, and is a structured, iterative approach to management that involves hypothesis testing through management action(s), monitoring, and feedback (ie adjusting management parameters). Although this concept has been well developed in both the scientific and legal literature (see Allen et al. 2011; Craig and Ruhl 2014), successful implementation of adaptive management is rare. Lack of authority in administrative law for agencies to deviate from static management plans is one barrier, while limited resources for experimentation and monitoring across ecosystems is another.

Recommendations for administrative law reform include allowing agencies to take an "adaptive management track" for appropriate projects (Craig and Ruhl 2014), and establishing procedural norms and safeguards to ensure that this track does not become an excuse for postponing action (Doremus 2001). This approach could allow for iterative recalibration between law and environmental management as monitoring data continue to provide better information about the system (Karkkainen 2002). Additionally, we recommend incorporating iterative planning strategies (eg "back-end" strategies) known as adaptive planning, which include feedback from monitoring into decentralized decision making, as increasingly seen in planning for climate change (Arnold 2010).

The identification of thresholds is critical for establishing an adaptive management track because, unlike equilibrium-based views of social-ecological systems, alternative regimes of systems are separated by thresholds (Folke et al. 2004). For example, lakes can shift from an oligotrophic regime to a eutrophic regime if a threshold in the phosphorus cycle is crossed (Figure 1). However, alternate regimes may be unknown due to uncertain responses to environmental change, and not all systems are characterized by multiple regimes. Thus, it is essential for any manager to establish whether the system being managed has the capacity to exhibit multiple regimes, and if so, to avoid crossing these thresholds (eg monitoring and managing for optimum phosphorus levels in a lake so that it remains oligotrophic).

Spatial and temporal scales in the ecosystems that are most vulnerable to global climate change may be so broad in extent that coordinated management becomes practically impossible. For instance, sub-Arctic lakes are vulnerable to global warming, a regional stressor threatening many of the ecosystem services these lakes provide. Recent research has demonstrated that it is possible to identify scales in these lakes that are relatively unaffected by regional stressors (eg warming or acid deposition; Angeler et al. 2013). In such cases, local management interventions may succeed in reinforcing structural and functional attributes at these scales, compensating for the loss of such attributes at unmanageable scales, and keeping systems in desirable regimes (McClanahan et al. 2011). As interventions are carried out, system feedback provides opportunities for recalibration of the thresholds, thereby reducing uncertainty (Allen et al. 2011).

If thresholds are categorized according to their relative uncertainty (eg highly certain, unknown) and adaptive management plans are tailored to accommodate the level of certainty as monitoring data help to identify thresholds, then agency actions could be based on an adaptive management plan. This adds a level of accountability to the adaptive management process and addresses the contention that many existing adaptive management plans are avoidance strategies against making difficult decisions or taking specific management actions (Doremus 2001). The trade-off between the social need for certainty and the ecological reality of change can be addressed through administrative laws that provide negotiated time frames for incremental change (Ruhl and Salzman 2010; Cosens 2013).

Adaptive management is particularly well-suited for environmental projects that have clear, distinct goals that are to be addressed by a single agency. For more complex systems - where multiple goals may conflict, 
where multiple agencies have jurisdiction, and/or where the system operates at multiple scales (see Panel 2) adaptive management is only part of the solution (Garmestani et al. 2013).

\section{Complexity}

Governance of social-ecological systems should account for complexity. Adaptive governance supports the integration of diverse, multilevel, formal institutions, informal groups or networks, and individual stakeholders for collaborative environmental management that incorporates adaptive management principles in a nested, overlapping system (Chaffin et al. 2014).

Networks of stakeholders bolster political, financial, and public support while also benefiting the process of information flow, providing a source for new ideas, expertise, and more informed decision making (Bodin and Crona 2009). Use of bridging organizations - formal organizations that strategically link actors and organizations external to their own staff or membership (Crona and Parker 2012) - has been shown to facilitate information flow across scales and to coordinate decision making across an overlapping and often conflicting system of multilevel government. For example, organizations such as the Columbia Basin Trust and the Northwest Power and Conservation Council, formally recognized at the federal level by the governments of Canada and the US, respectively, have increased information sharing and participation in decision making from the local to the international scale for issues affecting the Columbia River Basin (Cosens 2012).
Improved information flow is also needed from the public. Adaptive governance requires meaningful public participation in forms and forums much different from the current Administrative Procedures Act standards of public comment and response through engagement with citizens at the local level (Craig and Ruhl 2014). Those experiencing an environmental problem first-hand must be empowered to share information with the uppermost level of management so that appropriate resources can be released and the necessary responses to these problems can be coordinated. By tapping into local knowledge and linking local experts into stakeholder networks, the resulting system should be more nimble when responding to environmental change. Decision making is also better informed regarding trade-offs when those experiencing the environmental consequences of environmental change are given legitimate voice.

Matching the scale of governance to the scale of an ecosystem is difficult because complex systems rarely have clearly identifiable scales for governance (Ruhl and Salzman 2010), even if the dominant scales of structure and process present in the system can be objectively identified, such as the many sub-basins and tributaries of a watershed (Allen et al. 2014). Ecosystem-scale governance may be appropriate for coordinating programs across an entire watershed, but issues that arise may not require a response on such a large scale. Instead, responses may be adapted to the appropriate scale through a coalition of entities already collaborating through information exchange. For instance, the state of Oregon adopted and funded a system of watershed-based governance to restore salmon runs throughout the state

\section{Panel 2. Legislation and administration of adaptive management}

Adaptive management was developed in the 1970s to confront the complexities and uncertainties inherent in natural resource problems and issues (Holling 1978). Large degrees of technical and scientific uncertainty arise as ecosystems cross thresholds, undergo regime shifts, and exhibit the types of complex dynamics described by resilience theory (Holling 1973). Such uncertainties cannot be resolved prior to the development or implementation of policy, but must be dealt with through the evaluation of management "tests" of the policy. Adaptive management has been authorized (through legislation) for many resource systems, including the Columbia River Basin (Lee 1992), the Colorado River through the Grand Canyon, and the Florida Everglades (Gunderson and Light 2006). Constraints or failures of adaptive management in these systems have been ascribed to existing legislation such as the Endangered Species Act or Clean Water Act (Arnold and Gunderson 2013), yet others have attributed these constraints to the lack of adaptive governance (Garmestani et al. 2013). The Grand Canyon Adaptive Management Program (a product of the Grand Canyon Protection Act of 1992) is one of the few adaptive management programs where active ecosystem experimentation has led to improved understanding (Figure 2; Folke et al. 2005; Gunderson and Light 2006).

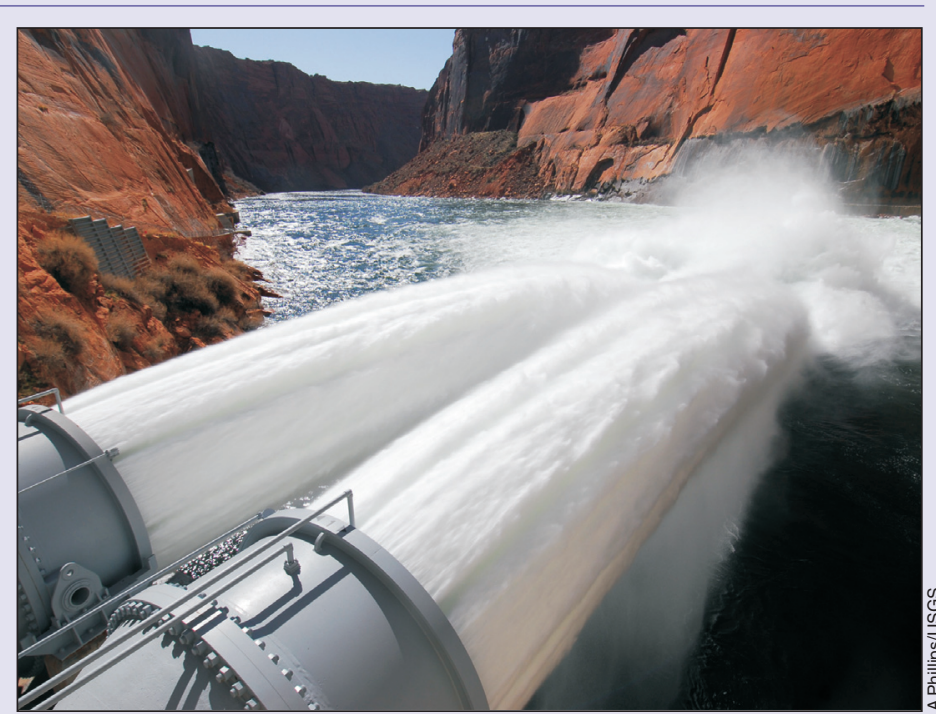

Figure 2. Experimental flow releases from the Glen Canyon Dam in March 2008. The managed water releases through these tubes were used to establish relationships between flood flows and the rebuilding of beaches and sandbars along the Colorado River in Grand Canyon National Park. 


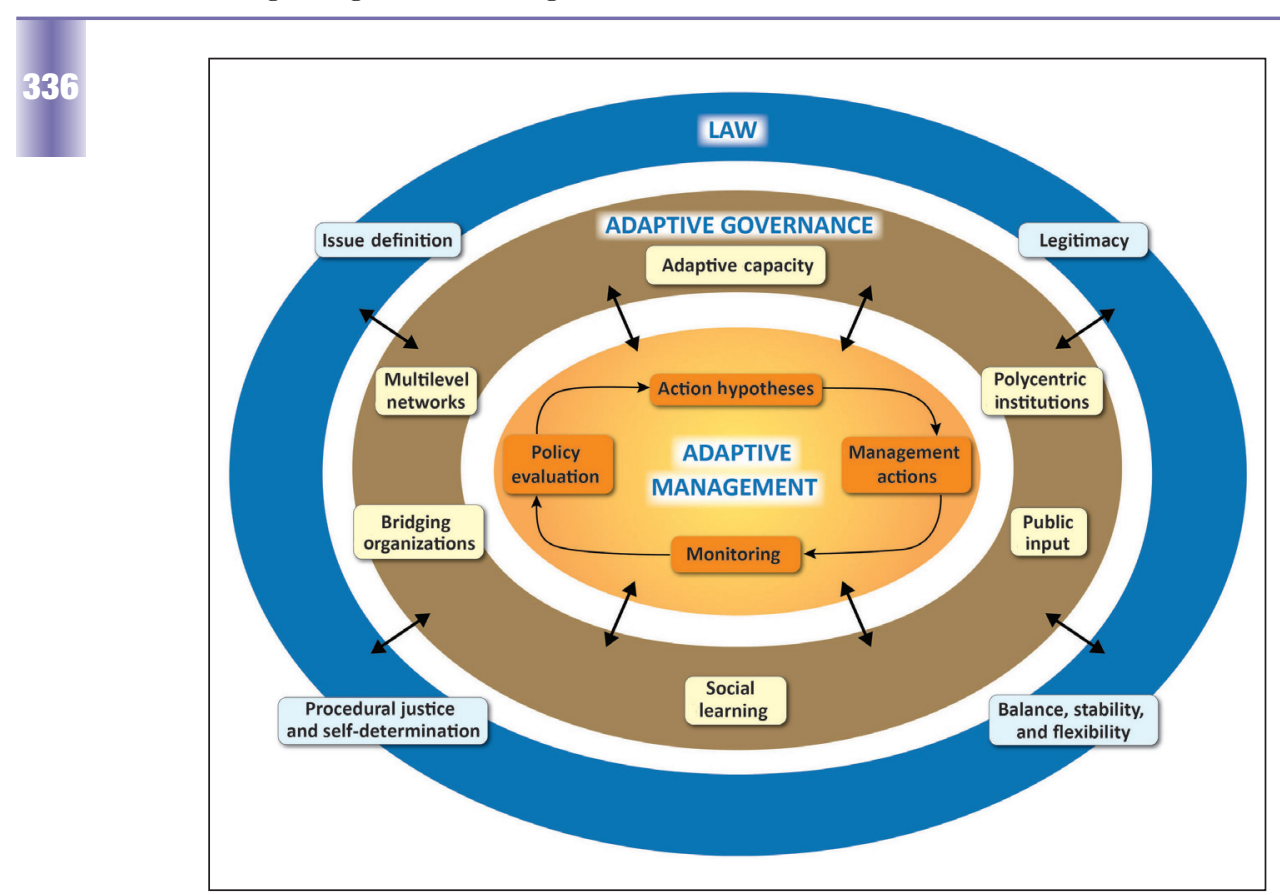

Figure 3. Stylized diagram of the relationships between adaptive governance, adaptive management, and the law. Law and legislation provide issue definition, social goals, and legitimacy in processes and procedures. Characteristics of adaptive governance (eg bridging organizations and informal networks) coordinate stakeholders and enable policy decisions (such as the introduction of adaptive management) that help direct learning processes to resolve uncertainties in resource management issues.

when certain species were granted protection under the US Endangered Species Act. Local watershed councils now work with landowners to implement innovative riparian restoration techniques, many of which are experimental and voluntary. This, in turn, helps in the process of information sharing as the lessons learned by local landowners are channeled up to state and federal regulators (Coe-Juell 2005).

\section{Conclusions and a way forward}

An adaptive system of governance is not necessarily at odds with the US constitutional division of authority between states and the federal government (Garmestani and Benson 2013). Principles such as cooperative federalism (ie federal and state government cooperatively regulate water and air quality through a system of permitting and enforcement) already dominate US environmental law and could be expanded to include governance at all scales (Figure 3).

Nevertheless, regulatory reform is necessary to permit active experimentation and scale-specific governance. For environmental problems that are largely local in nature, experimental reforms (Panel 2) to state and local laws may be sufficient as long as federal regulators permit states the necessary flexibility and authority to develop networks across and within levels of government and to include bridging organizations to connect various levels of governance and people (eg Ecomuseum Kristianstad
Vattenrike, Sweden; see Folke et al. 2005). This may serve to align social systems with the ecosystems they rely on, while maintaining institutions of governance developed for other legitimate reasons.

Much like disciplinary silos that need to be broken down to facilitate communication and integrated solutions, the institutional cultures of law and science must also be chipped away so that policy is better informed by science and so that scientists better understand the constraints and trade-offs of our legal system, especially with respect to how the US legal system addresses uncertainty and complexity.

\section{Acknowledgements}

The views expressed in this paper are those of the authors and do not represent the views or policies of the US Environmental Protection Agency. This research was conducted with the support of two postdoctoral appointments to the Research Participation Program at the National Risk Management Research Laboratory: one administered by the Oak Ridge Institute for Science and Education and one by the National Research Council Research Associateship Program. The Nebraska Cooperative Fish and Wildlife Research Unit is jointly supported by a cooperative agreement between the US Geological Survey, the Nebraska Game and Parks Commission, the University of Nebraska-Lincoln, the US Fish and Wildlife Service, and the Wildlife Management Institute. Funding was provided by the August T Larsson Foundation of the Swedish University of Agricultural Sciences. We thank T Eason for helpful comments.

\section{References}

Allen CR, Fontaine JJ, Pope KL, et al. 2011. Adaptive management for a turbulent future. J Environ Manage 92: 1339-45.

Allen CR, Angeler DG, Garmestani AS, et al. 2014. Panarchy: theory and application. Ecosystems 17: 578-89.

Angeler DG, Allen CR, and Johnson RK. 2013. Measuring the relative resilience of subarctic lakes to global change: redundancies of functions within and across temporal scales. J Appl Ecol 50: 572-84.

Arnold CA. 2010. Adaptive watershed planning and climate change. Environ Energy Law Policy J 5: 417-88.

Arnold CA and Gunderson L. 2013. Adaptive law and resilience. Environ Law Reporter 43: 10426-43.

Bodin O and Crona BI. 2009. The role of social networks in natural resource governance: what relational patterns make a difference? Global Environ Chang 19: 366-74.

Chaffin BC, Gosnell H, and Cosens BA. 2014. A decade of adaptive governance scholarship: synthesis and future directions. Ecol Soc 19: 56.

Coe-Juell L. 2005. The Oregon Plan: a new way of doing business. In: Brunner RD, Steelman TA, Coe-Juell L, et al. (Eds). 
Adaptive governance: integrating science, policy, and decision making. New York, NY: Columbia University Press.

Cosens B. 2012. Changes in empowerment: rising voices in Columbia Basin resource management. In: Cosens B (Ed). The Columbia River treaty revisited: transboundary river governance in the face of uncertainty. Corvallis, OR: Oregon State University Press.

Cosens B. 2013. Legitimacy, adaptation, and resilience in ecosystem management. Ecol Soc 18: 3.

Cosens B and Stow C. 2014. Addressing fragmentation and uncertainty in water allocation and water quality law. In: Garmestani AS and Allen CR (Eds). Social-ecological resilience and law. New York, NY: Columbia University Press.

Craig RK. 2010. "Stationarity is dead" - long live transformation: five principles for climate change adaptation law. Harvard Environ Law 34: 9-75.

Craig RK and Ruhl JB. 2014. Designing adminstrative law for adaptive management. Vanderbilt Law Rev 67: 1-87.

Crona B and Parker J. 2012. Learning in support of governance: theories, methods and findings to assess how bridging organizations contribute to adaptive resource governance. Ecol Soc 17: 32.

Doremus H. 2001. Adaptive management, the Endangered Species Act, and the institutional challenges of "new age" environmental protection. Washburn Law J 41: 50-89.

Folke C, Carpenter S, Walker B, et al. 2004. Regime shifts, resilience, and biodiversity in ecosystem management. Annu Rev Ecol Evol S 35: 557-81.

Folke C, Hahn T, Olsson P, et al. 2005. Adaptive governance of social-ecological systems. Annu Rev Env Resour 30: 441-73.

Garmestani AS and Benson MH. 2013. A framework for resilience-based governance of social-ecological systems. Ecol Soc 18: 9.

Garmestani AS and Allen CR. 2014. Social-ecological resilience and law. New York, NY: Columbia University Press.

Garmestani AS, Allen CR, and Benson MH. 2013. Can law foster social-ecological resilience? Ecol Soc 18: 37.

Graham NA, Jennings S, MacNeil MA, et al. 2015. Predicting climate-driven regime shifts versus rebound potential in coral reefs. Nature 518: 94-97.

Green OO, Garmestani AS, van Rijswick HFMW, et al. 2013. EU water governance: striking the right balance between regulatory flexibility and enforcement? Ecol Soc 18: 10.

Gunderson L and Light SS. 2006. Adaptive management and adaptive governance in the everglades ecosystem. Policy Sci 39: 323-34.

Holling CS. 1973. Resilience and stability of ecological systems. Annu Rev Ecol Syst 4: 1-23.

Holling CS. 1978. Adaptive environmental assessment and management. London, UK: Wiley and Sons.

Houck O. 2002. The Clean Water Act TMDL program. Washington, DC: Environmental Law Institute.

Karkkainen BC. 2002. Collaborative ecosystem governance: scale, complexity and dynamism. Virginia Environ Law J 21: 189-244.

Lee K. 1992. Compass and gyroscope: integrating science and politics for the environment. Washington, DC: Island Press.

McClanahan TR, Graham NA, MacNeil MA, et al. 2011. Critical thresholds and tangible targets for ecosystem-based management of coral reef fisheries. P Natl Acad Sci USA 108: 17230-33.

NRC (National Research Council). 2001. Assessing the TMDL approach to water quality management. Washington, DC: National Academies Press.

Ruhl JB. 1997. Thinking of environmental law as a complex adaptive system: how to clean up the environment by making a mess of environmental law. Houston Law Rev 34: 933-1002.

Ruhl JB and Salzman J. 2010. Climate change, dead zones, and massive problems in the administrative state: guidelines for whittling away. Calif Law Rev 98: 59-120.

Shapiro S and Glicksman R. 2004. Improving regulation through incremental adjustment. U Kansas Law Rev 52: 1179-248. 